\title{
The heavy-duty vehicle future in the United States: A parametric analysis of technology and policy tradeoffs
}

\author{
Amanda C. Askin*, Garrett E. Barter*, Todd H. West*, Dawn K. Manley* \\ Sandia National Laboratories \\ P.O. Box 969 \\ Livermore, CA 94551
}

\begin{abstract}
We present a parametric analysis of factors that can influence advanced fuel and technology deployments in U.S. Class 7-8 trucks through 2050. The analysis focuses on the competition between traditional diesel trucks, natural gas vehicles (NGVs), and ultra-efficient powertrains. Underlying the study is a vehicle choice and stock model of the U.S. heavy-duty vehicle market. The model is segmented by vehicle class, body type, powertrain, fleet size, and operational type. We find that conventional diesel trucks will dominate the market through 2050, but NGVs could have significant market penetration depending on key technological and economic uncertainties. Compressed natural gas trucks conducting urban trips in fleets that can support private infrastructure are economically viable now and will continue to gain market share. Ultra-efficient diesel trucks, exemplified by the U.S. Department of Energy's SuperTruck program, are the preferred alternative in the long haul segment, but could compete with liquefied natural gas (LNG) trucks if the fuel price differential between LNG and diesel increases. However, the greatest impact in reducing petroleum consumption and pollutant emissions is had by investing in efficiency technologies that benefit all powertrains, especially the conventional diesels that comprise the majority of the stock, instead of incentivizing specific alternatives.
\end{abstract}

Keywords: Heavy duty vehicle, Natural gas vehicle, Emissions,

Petroleum, Consumer choice

\footnotetext{
* Work: 925-294-3274 Fax: 925-294-3870

Email address: acaskin at sandia dot gov (Amanda C. Askin) Preprint submitted to Energy Policy

February 5, 2015
} 


\section{Introduction}

In the United States, heavy-duty vehicles (HDVs) accounted for $12.1 \%$ of total petroleum consumption in 2012 (Davis et al., 2014) and transported $70 \%$ of freight by tonnage (U.S. Department of Transportation Bureau of Transportation Statistics and U.S. Department of Commerce Census Bureau, 2012). These fractions are anticipated to grow in the future (U.S. Department of Transportation Federal Highway Administration, 2010). Accordingly, the efficiency and types of fuels used by HDVs are of increasing interest as the U.S. addresses climate stabilization and energy independence issues. Current federal efforts related to HDV efficiency include technology development, technology commercialization, and issuing regulatory standards. Examples of technology development and commercialization include the U.S. Department of Energy's 21st Century Truck Partnership, a publicprivate cooperative that has accelerated the pace of HDV efficiency improvements (National Research Council, 2012; U.S. Department of Energy: Vehicle Technologies Office, 2013), and the SuperTruck program, which has made substantial progress toward demonstrating a 50\% more freight efficient (measured in ton-miles per gallon) Class 8 tractor-trailer (TA Engineering, Inc., 2012). Example regulations include the new HDV fuel efficiency and greenhouse gas (GHG) emissions standards that took effect for model year 2014-2018 trucks (U.S. Environmental Protection Agency and U.S. Department of Transportation, 2011b). While fuel economy standards have been in place for light-duty vehicles (LDVs) since the 1970s, the diversity in construction, use, and ownership of HDVs has made it difficult to institute similar regulations for this segment of vehicles. Thus, these new regulations represent a significant accomplishment on behalf of both government 
and industry. Due to the short time horizon of the first round of regulations, the regulatory impact analysis focused on technologies that would be widely available in 2014, but did not consider more advanced efficiency technologies, hybridization, or alternative fuel vehicles (AFVs) (U.S. Environmental Protection Agency and U.S. Department of Transportation, 2011a). However, additional Presidential direction was issued to the EPA and the Department of Transportation in February 2014 to establish followon regulations by March 2016 that would begin to take these factors into consideration (The White House, 2014). Finally, interest in reducing HDV emissions and fuel consumption has also occurred at the state level. Prior to the enactment of federal fuel economy standards, the California Air Resources Board instituted regulations for tractor-trailers operating in California. These regulations require SmartWay certification (an EPA program that verifies technology performance) for new sleeper-cab tractors as well as adoption of other SmartWay technologies for both tractors and trailers (California Environmental Protection Agency, Air Resources Board, 2012).

Meeting stricter efficiency and emissions standards will require the continuous development of advanced technologies. A number of studies exist in the literature that attempt to quantify the range of efficiency and emissions benefits of individual, and groups of, technologies (National Research Council, 2010; Cooper et al., 2009; Silver and Brotherton, 2013; Zhao et al., 2013; Gao et al., 2013; Delorme et al., 2009). These studies play a key role in supporting near-term regulatory decisions as individual technologies must be considered in the context of specific use cases, given the diversity of HDV truck types and operational patterns. For instance, aerodynamics improvements of a long haul truck reduce fuel consumption by up to $11.5 \%$, but 
have far less impact on a refuse truck (National Research Council, 2010). Conversely, hybridization would have much greater utility for a refuse truck than for a long haul truck (National Research Council, 2010).

Alternative fuel HDVs represent both another potential pathway to meeting regulatory standards and could provide cost savings to fleet operators in their own right (Werpy et al., 2010; Whyatt, 2010). Well-informed commercial consumers are prepared to recognize and capitalize on the financial opportunities presented by low cost fuels, such as natural gas. The consistent usage patterns of some vocational vehicles and the capital resources of large fleets can enable the construction of on-site, private refueling infrastructure. Thus, the switch from diesel to an alternative fuel can happen rather quickly for a given fleet. Additionally, long haul trucks rely predominately on refueling infrastructure along highway corridors, thereby limiting the number of public alternative fuel stations necessary to support alternative fuel HDVs. Moreover, the high mileage of long haul vehicles enables their owners to recoup any initial capital outlay relatively quickly from a fuel price differential.

The short term decisions made today by policy makers and fleet owners to respond to the evolving environment of technology, regulations, economic growth, and commodity prices will have a lasting impact. The longer term, continuing evolution of the heavy-duty transportation sector will be sensitive to the uncertain trajectories of the same factors. As mentioned above, the literature includes studies of near-term impacts of specific technologies but is more limited in terms of long term projections or tradeoff studies. Long term studies that do exist (Cooper et al., 2009; National Petroleum Council, 2012; U.S. Energy Information Administration, 2014) are scenario- 
based and offer only a few possible futures, despite the extensive uncertainty in model inputs values. Furthermore, while numerous models have been developed to assess the long term fuel consumption and emissions trajectory of the LDV sector, due to the heterogeneity of the HDV sector and the relatively limited data availability, few models have considered the HDV sector in detail. To address these gaps, this paper presents a detailed HDV consumer choice and stock model to investigate the factors driving fleet adoption of efficiency technologies and alternative fuel vehicles. The results aim to provide insight into the inhibitors and drivers toward reduced petroleum consumption and emissions in the HDV sector. Critical to this analysis is the parameterization of inputs to capture uncertainties, determine sensitivities, and illustrate long term tradeoffs in these objectives.

\section{Methods}

The model tracks the evolution of the heavy-duty vehicle stock in the US, its fuel usage, and corresponding demand for raw energy stocks. A diagram of the model is shown in Figure 1 and is based on a similar implementation for light-duty vehicles described in Barter et al. (2013). The model is broken down into three sub-components: a vehicle sub-model, a fuel production sub-model, and an energy supply sub-model. The sub-models exchange price and demand information for the energy supply stocks and fuels considered. No predetermined market share targets are assumed, thus technologies compete directly in the marketplace and are allowed to flourish or fail. The model is implemented using system dynamics concepts (i.e., stocks, flows and feedback loops) to construct a set of interacting algebraic and differential equations using Python and the Numpy library. Solutions 
are generated using a third-order Runge-Kutta algorithm with fixed step size.

[Figure 1 about here.]

\subsection{Model Scope}

Gross Vehicle Weight (GVW) Class 7 and 8 vehicles are the largest heavy-duty consumers of fuel and comprised 17\% of 2012 U.S. transportation petroleum use (12\% of total U.S. petroleum use) (Davis et al., 2014). By contrast, Class 3-6 vehicles consumed only 4\% of transportation fuel use in 2012. The model therefore focuses exclusively on Class 7 and 8 heavyduty vehicles in the US with the following exclusions:

- Public vehicles whose adoption is often politically motivated and/or based on individualized circumstances $(3.9 \%$ of Class 7 and 8 petroleum consumption (R. L. Polk \& Co., 2012));

- Emergency vehicles which have very specific operating conditions and purchasing considerations $(0.5 \%$ of Class 7 and 8 petroleum consumption (R. L. Polk \& Co., 2012));

- Recreational vehicles which are not typically commercially operated or purchased with business considerations;

- Short-term rental vehicles for which the user is frequently changing and always different than the permanent owner (6.4\% of Class 7 and 8 petroleum consumption (R. L. Polk \& Co., 2012));

- Off road vehicles, construction equipment, and farm equipment which are separately regulated and have unique operating conditions. 
The model currently considers natural gas as the only alternative fuel due to the availability of suitable engines and industry interest in natural gas as a fuel for commercial fleets. Compressed natural gas (CNG) and liquefied natural gas (LNG) are considered separately due to their applicability to different niches. LNG has a higher-energy density that is well suited for long distance travel, but it also requires expensive liquefaction and handling infrastructure. Additionally, LNG boil-off gas losses may reduce overall efficiency unless the fuel is used quickly. CNG requires compressors that can be installed on-site, but it has comparatively lower energy density (shorter vehicle range) and thus is more suited to urban operations. Other alternative powertrains, such as biodiesel, electric vehicles, and hydrogen fuel-cell vehicles, are not currently included for various reasons. While biodiesel can be mixed with diesel in small proportions (i.e., B20, 20\% biodiesel, $80 \%$ petrodiesel), using biodiesel exclusively requires engine modifications that are not forthcoming from manufacturers. Similarly, hydrogen fuel cell vehicles are technically feasible, but are too far from market-ready to be sufficiently characterized in the model. Finally, electric vehicles do not currently scale well to heavy-duty applications due to the tradeoff between battery capacity and freight capacity.

In terms of efficiency improvement technologies, the model captures their performance and cost impacts in aggregate. This approach is motivated by the variety and number of technologies available and the wide ranges of estimates of their effectiveness under various operating conditions. Example technologies include aerodynamic improvements, wide-based single tires, low-viscosity lubricants, automatic tire inflation, idle reduction technologies, and weight reduction. Considering aggregations of technologies allows 
parameterization across the cost and performance tradespaces to provide insight on thresholds to achieve market success.

Changes in vehicle operation procedures can also improve the energy efficiency of HDVs. These changes could include improving logistics, shifting goods transport to more efficient transportation modes, using longer combination vehicles, speed limiting, and other forms of driver behavior modification. These innovations are not considered in the model because of their interaction with safety and logistical constraints, which are difficult to capture, as well as our desire to focus on technologies.

The following sub-sections describe the model implementation in detail. To make the model development tractable and focused on our analysis questions of interest, a number of assumptions are inherent to the model design. Notable model assumptions that are not otherwise discussed in the text include the following:

- A load specific fuel consumption metric is used (fuel consumption per ton-mile) in accordance with recommendations made by the National Academy of Sciences (National Research Council, 2010). This metric differs from the miles per gallon metric commonly used for light-duty vehicles and reflects the load-carrying purpose of HDVs.

- The growth in HDV stock ton-miles per year is exogenous to the model (U.S. Department of Transportation Federal Highway Administration, 2010), and therefore inter-modal shifting of freight traffic in response to fuel or vehicle price (i.e., rebound effect) is not considered.

- The model does not consider fuel use or efficiency improvements for on-board vocational equipment, such as cement mixing or refuse truck 
hydraulics.

- Conversions of used trucks from one powertrain to another after customer delivery are not considered. Powertrain conversions of new trucks done by OEMs or other suppliers prior to customer delivery are considered.

- Although real world tractors are not necessarily paired with a dedicated trailer, for the purposes of the model combination tractortrailers are considered as joined units.

- Vehicle maintenance costs are assumed to be the same for all powertrains. Since there is a lack of available data on the cost and frequency of HDV maintenance, all vehicle maintenance costs are excluded from the model.

\subsection{Vehicle Modeling}

\subsubsection{Vehicle Segmentation}

The model starts in 2012 with 3.38 million Class 7 and 8 heavy-duty vehicles in service in the United States that fall within our scoping assumptions. The initial truck stock is derived from Polk data (R. L. Polk \& Co., 2012) and segmented by the following seven dimensions:

1. Age: 0-17 years. Subscript, $a$;

2. State: 48 CONUS states and the District of Columbia. Subscript, $r$;

3. $G V W$ : Class 7 or 8. Subscript, $g$;

4. Body: Single unit or combination tractor-trailer truck. Subscript, $b$; 
5. Powertrain: Compression ignition diesel (CI), CI electric or hydraulic hybrid (CIHYBRID), CI SuperTruck technology platform (CIST), CIHYBRIDST, compressed natural gas spark ignition (CNG), CNGHYBRID, CNGST, liquefied natural gas (LNG), and LNGST. Subscript, $n$;

6. Fleet size: 0-10 trucks, 10-100 trucks, 100-1000 trucks, and more than 1000 trucks. Subscript, s;

7. Refueling station type: Highway truck stop, local gas station, or private infrastructure (this segment is initialized by statistics from the VIUS2002 database (U.S. Census Bureau, 2002)). Subscript, $t$.

The vehicle stock, $\mathcal{V}$, can therefore be written as,

$$
\mathcal{V}=\mathcal{V}_{\text {argbnst }}
$$

Heavy duty truck stock growth is assumed to scale with expected growth in on-road freight demand, which is derived from the Freight Analysis Framework (FAF) model (U.S. Department of Transportation Federal Highway Administration, 2010). Specifically, the percentage growth in total onroad truck ton-miles, as predicted by the FAF model, is the assumed percentage growth in truck stock for the same year. Thus, we implicitly assume that the ton-mile allocation per truck for each model segment is constant over time and that total ton-miles for all segments, except for the choice of powertrain, grow uniformly. The constant values of ton-miles are derived from the VIUS2002 survey database (U.S. Census Bureau, 2002) based on age, GVW, body type, and refueling station type $\left(\mathcal{M}=\mathcal{M}_{\text {agbt }}\right)$. Truck scrap rates are taken from survival probability curves used by the EPA for 
recent rule making (U.S. Environmental Protection Agency and U.S. Department of Transportation, 2011a), which vary over truck age, GVW, and body type $\left(\mathcal{W}=\mathcal{W}_{a g b}\right)$. Scrap rates are also assumed to be constant over time and independent of powertrain. The evolution of each vehicle segment can therefore be written as,

$$
\frac{\mathrm{d} \mathcal{V}_{a=0, r g b n s t}}{\mathrm{~d} t}=\sigma_{\text {rgbnst }}^{V} \mathcal{S} \sum_{a n} \mathcal{V}_{\text {argbnst }} ; \quad \frac{\mathrm{d} \mathcal{V}_{\text {argbnst }}}{\mathrm{d} t}=\mathcal{W}_{\text {agb }} \mathcal{V}_{\text {argbnst }}
$$

where $\mathcal{S}$ is the overall sales rate, $\mathcal{W}$ is the scrap rate, and $\sigma^{V}$ is the consumer sales fraction by powertrain for each vehicle segment such that, $\sum_{n} \sigma_{r g b n s t}^{V}=$ 1. The sales rate is obtained by the difference between the overall growth and scrap rates.

Used truck sales are not captured in the model due to a lack of available data on used truck transactions. However, the migration of aged trucks from particular segments to others is captured to maintain the appropriate truck age distribution for different segments. Thus, while all model segments are assumed to grow uniformly, by shifting trucks from large fleets and long haul segments to smaller fleets and urban segments, new truck purchases are biased towards larger fleets with greater access to capital and higher mileage vehicles. Specifically, the relative distribution of truck ages for every fleet size-station type as represented by the VIUS2002 survey (U.S. Census Bureau, 2002) is restored prior to computing the total demand for new trucks per segment. While this approximation does not precisely model the secondary truck market, it does ensure that the HDV stock is appropriately distributed across usage segments. 
Ton-mile fuel economy for existing trucks on the road and future model years is derived from a variety of data sources. Efficiency data for existing trucks is taken from EIA AEO reports dating back to the 1990s (U.S. Energy Information Administration, 2014). New trucks in model years 2014-2017 are assumed to comply with the new NHTSA/EPA regulations (U.S. Environmental Protection Agency and U.S. Department of Transportation, 2011a). The NHTSA/EPA regulatory impact analysis also provided the template for converting the EIA efficiency data from miles per gallon to ton-miles per gallon. Efficiency data beyond 2017 for CI, CIHYBRID, and CNG/LNG trucks were taken from analysis files publicly available from the National Petroleum Council (2012). The quantitative efficiency improvement of the SuperTruck powertrain variants was taken from TA Engineering, Inc. (2012). This study calculated a 50\% improvement at SuperTruck introduction in 2015, which declines to a $33 \%$ improvement by 2050 , due to technology diffusion into the conventional powertrains. These improvement factors were further parameterized in our analysis. Finally, to account for LNG boil-off and ullage (the unusable fuel tank capacity to allow for gasphase natural gas and venting), LNG trucks using gas stations or private infrastructure (indicating short haul, non-continuous operation), were penalized $10 \%$ in ton-mile efficiency. This value is an approximation as no firm numbers could be found in the literature. However, no ullage penalty was imposed on LNG trucks using truck stops (i.e., engaged in long haul operations where continuous use minimizes the impact of boil-off). 


\subsubsection{Vehicle Purchase Model}

The segment sales fractions in each time-step, $\sigma^{V}$, are assigned using a logit choice model (Struben and Sterman, 2008). The sales fraction for a given segment is determined by,

$$
\sigma_{\text {rgbnst }}^{V}=\frac{k_{n} \theta_{r n t} \mathcal{U}_{r g b n s t}^{V}}{\sum_{n} k_{n} \theta_{r n t} \mathcal{U}_{\text {rgbnst }}^{V}} ; \quad \mathcal{U}_{\text {rgbnst }}^{V}=\exp \left(-\beta \frac{\mathbb{C}_{\text {rgbnst }}^{G}}{\left\langle\mathbb{C}_{r g b n s t}^{G}\right\rangle_{n}}\right)
$$

where $\mathcal{U}^{V}$ is the utility, $\beta$ is the logit exponent, $\mathbb{C}^{G}$ is the total cost, and $\langle\cdot\rangle_{n}$ is a reference cost taken to be the average cost over all powertrains. The baseline logit exponent value is $\beta=25$, which gives an elasticity of -6 (a $6 \%$ drop in demand for a $1 \%$ increase in price at $50 \%$ market share). For reference, studies of the light-duty market report elasticities anywhere from -1 to -8 (Greene, 2001). In truth, $\beta$ is an uncertain parameter that is included in our sensitivity studies. The utility shares are limited by powertrain availability, $k$, and willingness-to-consider an alternative fuel based on infrastructure availability, $\theta$. The only powertrain availability limitation is that the SuperTruck powertrain variants are assumed to be available starting in 2015. Otherwise all other powertrains are assumed to be made-to-order, so there is no limit on the number of vehicles available. It is acknowledged that this assumption may overestimate early adoption of cutting-edge technology. Finally, the willingness-to-consider function is a logit curve based on the ratio of alternative fuel stations relative to diesel 
stations in a given state,

$$
\theta_{r n t}=\left[1+\exp \left(-\frac{\phi_{r n t}-\theta_{t}^{0}}{\theta^{1}}\right)\right]^{-1} ; \quad \phi_{r n t}=\frac{\sum_{f \in n} \Phi_{r t f}}{\Phi_{r t, f=\text { diesel }}}
$$

where $\theta^{0}$ is an input parameter that centers the logit curve, $\theta^{1}$ controls the logit slope, $\phi$ is the alternative fueling station ratio, $\Phi$ is the absolute number of alternative fueling stations, and the subscript $f$ refers to the fuel. The default values for the constants are $\theta^{0}=0.1$ (Sperling and Kitamura, 1986) and $\theta^{1}=0.02$ (an approximation). $\theta^{0}$ is included in the model parameterization. Note that $\theta=1$ for fleets that use private refueling.

The generalized vehicle purchase cost is amortized over a payback period and converted to a per ton-mile cost using the annual ton-miles traveled.

$$
\mathbb{C}_{r g b n s t}^{G}=\mathbf{A}_{s}\left(\frac{\mathbb{C}_{g b n t}^{V}}{\mathcal{M}_{a=0, g b t}} ; \mathcal{L}_{s}\right)+\mathbb{C}_{r g b n t}^{F}+\frac{\mathbb{C}_{g b n t}^{P}}{\mathcal{M}_{a=0, g b t}}
$$

where $\mathbb{C}^{V}$ is the vehicle capital cost, $\mathbb{C}^{F}$ is the fuel cost per ton-mile, $\mathbb{C}^{P}$ is the penalty cost, $\mathcal{L}$ is the required payback period, and $\mathcal{M}$ is the annual tonmiles per truck. The function, $\mathbf{A}_{s}(\cdot ; \mathcal{L})$, amortizes the cost to the consumer over an implicit or required payback period (i.e., the longest period the buyer is willing to accept investment payoff) with no discounting. Amortizing the entire vehicle capital cost is consistent with the assumption that the sale of depreciated used trucks is not captured. Recall that the migration of used trucks from particular usage segments to others is captured though, as described above.

To capture the differences between small fleet consumers, who might 
have limited access to capital, and larger fleet consumers, who likely have greater access to capital, the required payback period, $\mathcal{L}$, is a function of fleet size,

$$
\mathcal{L}_{s}= \begin{cases}L^{0}, & \text { Fleet size } 0-10 \\ L^{0}+\left(L^{1}-L^{0}\right) / 3, & \text { Fleet size } 10-100 \\ L^{0}+2\left(L^{1}-L^{0}\right) / 3, & \text { Fleet size } 100-1000 \\ L^{1}, & \text { Fleet size }>1000\end{cases}
$$

where $L^{0}$ and $L^{1}$ are user parameters defining the required payback period for the smallest and largest fleets, respectively. Linear interpolation is used for the intermediate fleet sizes. Default values are estimated at $L^{0}=0.75$ years and $L^{1}=2.5$ years with an average value of 1.625 years. Additionally, since this variation of payback period as a surrogate for access to capital is an approximation, it is prominently featured in the parametric studies.

Similar to vehicle efficiency data, vehicle purchase costs, $\mathbb{C}^{V}$, are taken from a few different sources, as no single source provided all the data necessary. The future costs of CI Class 8 combination tractor trailers, as well as the cost premiums for hybridization and natural gas (both CNG and LNG) powertrains are taken from the National Petroleum Council (2012). Some smoothing of the data was done to ensure monotonicity. The hybridization cost premiums however led to suspect sales rates and was therefore corrected to match estimates from Gao et al. (2013). The SuperTruck powertrain variants were assigned costs based on TA Engineering, Inc. (2012), which predicted declining purchase premiums over time due to diffusion of 
the high efficiency technologies. Cost differentiation between Class 7 and Class 8 vehicles, day cab versus sleeper cab, and combination tractor trailers versus single unit trucks, was derived from Polk data (R. L. Polk \& Co., 2012). It was assumed that tractor trailers using highway truck stops would use sleeper cabs, but tractor trailers in urban operations would otherwise use day cabs.

A penalty cost, $\mathbb{C}^{P}$, is included to quantify limitations of alternative powertrains in terms of fuel tank range and time spent refueling. This penalty is computed as an annual estimate of the time spent at the pump and is expressed as,

$$
\begin{aligned}
& \mathbb{C}_{g b n t}^{P}=\delta_{t}^{P} \sum_{f} \frac{\mathcal{M}_{a=0, g b t}}{\eta_{a=0, g b n t f} \mathcal{H}_{t f}} ; \quad \delta_{t}^{P}= \begin{cases}\$ 0 / \mathrm{hr}, & \text { private refueling } \\
\$ 30 / \mathrm{hr}, & \text { else }\end{cases} \\
& \mathcal{H}_{t f}= \begin{cases}10 \mathrm{gal} / \mathrm{min}, & \text { Diesel at a gas station } \\
60 \mathrm{gal} / \mathrm{min}, & \text { Diesel at a truck stop } \\
0.05 \mathrm{dge} / \mathrm{min}, & \mathrm{CNG} \text { private overnight compressor } \\
4 \mathrm{dge} / \mathrm{min}, & \mathrm{CNG} \text { otherwise } \\
45 \mathrm{dge} / \mathrm{min}, & \mathrm{LNG}\end{cases}
\end{aligned}
$$

where $\mathcal{H}$ is the refueling rate, $\eta$ is the fuel economy, and $\delta^{P}$ monetizes time. The refueling rate values are taken from pump manufacturer specifications and EPA regulations. No penalty is applied for private refueling because it is assumed to occur after-hours and not detract from vehicle operation. The estimation of the penalty value for public refueling is, of course, an 
approximation and is therefore also included in our parameterization.

The fuel cost per ton-mile, $\mathbb{C}^{F}$, is simply the product of the fuel price and the fuel consumption per ton-mile of a vehicle,

$$
\mathbb{C}_{r g b n t}^{F}=\left(1+q_{n t}\right) \sum_{f} \mathbb{P}_{r t f}^{F} \Xi_{a=0, g b n t f} ; \quad \Xi_{a g b n t f}=1 / \eta_{\text {agbntf }}
$$

where $\mathbb{P}^{F}$ is the price of fuel, $\Xi$ is the fuel consumption per ton-mile, and $q$ is a user-defined multiplier for the operation of private infrastructure. This parameter represents the cost of buying, operating, and maintaining private refueling equipment and is appended to the fuel cost as a percentage increase. In this way, the cost scales appropriately for large vs. small fleets and high vs. low ton-mileage vehicles. The default value of $q$ for natural gas vehicles, above and beyond diesel vehicles, is assumed to be 0.2 (U.S. Department of Energy, 2014), meaning that for every dollar spent on fuel, another 20 cents is spent on buying, operating, and maintaining the private infrastructure.

\subsubsection{Infrastructure Growth and Total Fuel Demand}

The model tracks the number of public refueling stations by region. The ratio of alternative fuel pump stations to alternative fuel vehicles (in the thousands) is denoted the Vehicle Refueling Index (VRI) (Yeh, 2007), and is a surrogate for infrastructure growth in our model,

$$
\frac{\mathrm{d} \Phi_{r t f}}{\mathrm{~d} t}=(V R I) \sum_{g b s, n \in f} \frac{\mathrm{d} \mathcal{V}_{a=0, r g b n s t}}{\mathrm{~d} t}
$$

The VRI is a policy-driven input parameter that scales with the number of AFVs purchased in a given region to determine the number of new alter- 
native refueling stations added. The default value is $V R I=0.5$, meaning that there is a new station added for every 2,000 new vehicles. By parametrically adjusting the VRI, the model can explore the dependency between powertrain adoption and refueling infrastructure growth. Thus, infrastructure investment is not directly captured, but is assumed to dynamically respond to sales. The initial refueling station distribution by region and fuel type for natural gas fuels is taken from U.S. Department of Energy (2012). The initial number of diesel stations, 32,508 with 5,000 being truck stops (TIAX LLC, 2012), was assumed to be distributed across regions in the same proportion as diesel trucks.

As shown in Figure 1, the vehicle sub-model outputs the total fuel use demand, $\mathbb{D}^{F}$. This is computed by an accounting of the total ton-mileage covered by the HDV stock and the fuel consumption rate,

$$
\mathbb{D}_{r f}^{F}=\sum_{\text {agbnst }} \mathcal{V}_{\text {argbnst }} \mathcal{M}_{\text {agbt }} \Xi_{\text {agbntf }}
$$

\subsection{Fuel Production and Commodity Supply}

The fuel production and supply sub-models are qualitatively described here. A mathematical description of their inner workings can be found in Barter et al. (2013). The fuel module calculates the cost and energy source mix of transportation fuels, given fuel demand from the vehicle model and energy source costs from the energy source sub-model. The set of fuels in the model is diesel, CNG, and LNG. The fuel derived demand in each state is matched with the corresponding raw energy feedstocks using conversion efficiencies specified by the GREET model (Argonne National Laboratory, 2014). State-by-state pricing variations, including taxes, taken from actual 
pricing data are enforced for diesel and natural gas due to the complexities of the supply and refining network for those fuels. Well-to-pump and pump-totailpipe emissions are computed using process estimates from GREET and the total fuel demand. The model tracks emissions of $\mathrm{CO}_{2}$-equivalent GHG, volatile organic compounds (VOCs), carbon monoxide $(C O), 10$ micron particulates $\left(P M_{10}\right), P M_{2.5}$, oxides of nitrogen $\left(N O_{x}\right)$, and oxides of sulfur $\left(S O_{x}\right)$.

The U.S. Energy Information Administration (2014) Annual Energy Outlook reference case was our source for crude oil, coal, and natural gas prices. Crude oil and coal were assumed to be global and national commodities, respectively, with prices unaffected by perturbations in US fuel demand. Natural gas prices, as reported by the EIA, varied by region, but were similarly assumed to be unaffected by transportation demand.

\section{Results and Discussion}

\subsection{Model Parameterization and Baseline Inputs}

For many of the input cost and efficiency projections in the model, a multiplier approach was used to parameterize the values. Thus, instead of independantly varying each data point in the oil price projection through 2050, a multiplier that scales from 1 at the simualtion start to a user-defined value in 2050 was used instead. Examples for parameterization of commodity prices, truck purchase prices, and truck efficiency values are shown in Figure 2. The multiplier implementation captures the growing cone of uncertainty further out in time. Other model inputs that are constant in time, such as required payback periods or infrastructure growth rates, were varied directly. Furthermore, the parameter ranges shown in the analysis are 
not intended as expectations of future values, but rather capture potential bounding cases. All input variables and parameter distributions are assumed to be independent, which likely breaks down in some regions of the tradespace. For instance, high diesel prices would likely compel fleet owners to consider longer payback periods (Puller and Greening, 1999). Thus, while a complete tradespace is shown in the analysis, some regions might be more likely to occur than others.

[Figure 2 about here.]

Figure 2 shows some of the key prices and efficiencies that dictate model results. All dollar values shown are 2012USD. Both baseline oil and natural gas price projections, shown in Figure 2a, are expected to rise over the course of the simulation (U.S. Energy Information Administration, 2014). Oil prices are slated to rise more sharply starting in 2015, which is reflected in the fuel price projections in Figure 2b. Note that fuel prices are technically a model output, but are closely tied to feedstock prices which are inputs. Vehicle purchase costs for CI powertrains are anticipated to rise as fuel efficiency and emissions regulations become more stringent and more advanced technologies diffuse into the market place (National Petroleum Council, 2012). This gradual rise actually impacts all powertrains, but the NGVs also benefit from early cost decreases as higher manufacturing volumes and targeted technology development reduce CNG and LNG purchase premiums. Finally, the vehicle efficiencies shown in Figure 2d show (mostly) monotonic increases over the course of the simulation, reflecting improving technology and higher efficiency standards (National Petroleum Council, 2012). There is a slight decrease in vehicle efficiency around 2017, which 
stems directly from the new HDV regulations as an allowance for stricter emissions standards (U.S. Environmental Protection Agency and U.S. Department of Transportation, 2011a). Note that for Figures 2c and 2d, only one powertrain parameterization is shown, but similar shaded parameterization ranges exist for the other powertrains as well.

The continuous march of efficiency improvements for all powertrains has a significant impact on emissions intensity as well. The projected emissions intensity for Class 8 trucks in terms of mass emitted per ton-mile is shown in Figure 3. These plots are produced by combining the efficiency projections in Figure 2 with well-to-wheel emissions rates from the GREET model (Argonne National Laboratory, 2014). It is worth reiterating that emission rates are constant over time for a given fuel, and specific scrubbing technologies are not modeled. The commonly held notion that NGVs are cleaner than diesel vehicles in terms of particulate, $N O_{x}$, and GHG emissions can fall apart if, as projected, the fuel efficiency deficit for NGVs increases slightly in the future. Per unit energy, natural gas burns cleaner than diesel, but the lower fuel economy of NGVs compared to compression ignition diesels offsets this benefit. While natural gas powertrains have lower PM2.5, $N O_{x}$, and GHG intensities than the CI powertrain at the simulation start, this is not necessarily true at simulation end. The CIST powertrain in particular has a lower emissions intensity per ton-mile than the CNG powertrain. When considering the uncertainties in future technology performance, and the regulatory stringency associated with criteria pollutants, this is an important dynamic that is explored below.

[Figure 3 about here.] 


\subsection{Baseline Model Predictions}

The HDV sales totals and stock fractions for baseline input values are shown in Figure 4. It is immediately apparent that traditional diesel trucks have a long future in the heavy-duty market in this scenario. CI powertrains are projected to be more than $80 \%$ of the HDV stock through 2050 . By that time, the HDV stock is projected to be about $11 \%$ NGVs (translating to approximately 20,000 truck sales in 2050), with more CNG trucks than LNG trucks. While the projected numbers of hybrids of any fuel type are minimal, there is a notable market fraction of CI SuperTrucks. The absolute number of truck sales in the model is shown in Figure 4b. The jagged growth envelope, including the regulation pre-buy in 2014 and the jump in 2035, is taken directly from the exogenous FAF data (U.S. Department of Transportation Federal Highway Administration, 2010), a model inputs. Figure 4c shows the baseline load specific fuel consumption (total fuel consumption divided by total ton-mileage) over the course of the simulation. The number of trucks on the road and ton-mileage traveled nearly doubles, but the number of diesel-equivalent gallons (DGE) used per ton-mile decreases by more than half, reflecting the projected improvement in fuel consumption technology. Also, the number of DGEs of CNG and LNG is nearly equal, despite there being many more CNG trucks on the road than LNG trucks. This suggests that LNG trucks are being adopted in higher mileage operations, which is explored is greater detail throughout this analysis.

[Figure 4 about here.] 
The cumulative stock profile is broken down further in Figure 5. Figure 5a shows the powertrain fractions over time according to fleet size. As explained in Section 2, bigger fleets are given longer required payback periods to account for greater access to capital. Thus, it makes sense to see increasing proportions of NGVs and SuperTruck technology platforms as the fleet size progresses from ones to tens to hundreds to thousands. The difference in required payback periods is significant enough to lead to CIs being $70+\%$ of the stock of large fleets in 2050, but as high as $90 \%$ in the smallest fleets. It should be noted that these differences are not wholly attributable to the difference in required payback periods, as there are other factors correlated with fleet size, such as public vs. private refueling or urban vs. long haul operations. Alternative powertains percolate into the smaller fleets primarily through the migration of aged trucks and only occasionally through new truck sales.

[Figure 5 about here.]

The differentiation across segments is even more stark in Figure 5b, which shows the HDV stock breakdown by refueling location. The Gas Station segment captures smaller fleets conducting urban operations and has almost zero NGVs even by 2050. In contrast, the Private refueling segment is also comprised of HDVs conducting urban trips, but in fleet sizes large enough to support their own infrastructure. This segment has by far the greatest adoption of NGVs, specifically CNG trucks, because fuel cost savings can quickly offset vehicle and infrastructure purchase premiums. With shorter distance, urban trips, the drawbacks of the CNG powertrains (i.e., reduced fuel tank capacity) have minimal consequence. The final segment, 
Truckstop refueling, reflects predominantly long haul Class 8 tractor trailers, the segment with the largest ton-mileage and fuel consumption. This segment is also dominated by CI powertrains through 2050, with a noticeable adoption of diesel SuperTruck variants, but surprisingly few LNG trucks. This could imply that while CNG truck ownership makes economic sense in the model, there is less of a financial advantage to LNG ownership. Recall that CNG and LNG prices are not equal, with CNG cheaper by about $\$ 0.90$ per DGE (Figure 2b). This dynamic will be explored in greater depth below.

\subsection{Competition Between Powertrains}

The model is comprised of only diesel and natural gas trucks. Thus, the gains of one powertrain category are the losses of the other. This give-andtake is depicted in Figure 6. Sales fractions of all diesel trucks in 2050 versus variations in oil and natural gas commodity prices are shown in Figure 6a. The diagonal contour lines show that both natural gas and oil prices are equally influential in determining the sales breakdown between diesel and natural gas trucks. This reinforces that it is the fuel price differential, not necessarily the absolute prices, that influences the viability of alternative fuel powertrains. Other factors that directly influence the competitiveness of heavy-duty NGVs, specifically their cost premium and efficiency deficit, are shown in Figure 6b. A multiplier value of zero in these plots implies zero difference with the CI powertrain in 2050 and a multiplier value of one implies that the baseline projections for cost and efficiency differences are maintained. Higher cost multiplier values mean higher purchase premiums, relative to CI costs, and higher efficiency multiplier values correspond to 
a bigger efficiency deficit. The contour lines here are nearly vertical and showing much greater sensitivity to the cost-axis than the efficiency axis. If the purchase premium was minimal, more than half of all trucks sold in the model would be NGVs. Interestingly, if the NGV purchase premium did go to zero, it is the use of urban CNG trucks in private fleets that truly benefit (Figure 6c). Some wider adoption of long haul LNG trucks is observed, but far less than might be anticipated. As the NGV purchase premium goes to zero, LNG trucks supplant diesel SuperTrucks in the long haul segment, suggesting those two powertrains could be in competition with one another.

[Figure 6 about here.]

The tradespace between oil prices and the average required payback period in Figure 7a shows interesting contour line slope changes. At baseline oil price projections, extending the average required payback period (moving up the $y$-axis), essentially encouraging fleet owners to take a longer view on ownership costs, has little impact on NGV sales. In contrast, if oil prices were 50-100\% higher, extending the required payback period can significantly impact NGV sales. This implies that NGVs are much more competitive when oil prices are higher, but at current projections, other powertrains make more economic sense at longer required payback periods. Figure $7 \mathrm{~b}$ confirms that it is diesel SuperTrucks that are preferred at longer required payback periods and baseline oil price projections. Moving along the $x$-axis in Figure $7 \mathrm{~b}$, as oil becomes more expensive, consumers first look to more efficient diesel powertrains, such as CIST, but at even higher oil prices switch to NGVs. Given the dynamics observed in Figure 6c, this competition is arising specifically in the long haul segment between CIST 
and LNG trucks.

[Figure 7 about here.]

As a government-sponsored program, it is interesting to examine the impact of the SuperTruck platform by running the model with and without those powertrains available to consumers. From Figure $7 \mathrm{~b}$ it is clear that SuperTruck adoption is sensitive to the required payback period, thus Figure 7c depicts the benefit in terms of reductions in GHG emissions and petroleum consumption relative to the average required payback period. At short required payback periods, there is no observable impact of the SuperTruck powertrains, but by periods of 5 years, there is at least an additional 5 percentage point reduction in GHG emissions and a couple of percentage points in petroleum use reduction. It should be noted that the value of the SuperTruck program extends well beyond adoption of the SuperTruck powertrains in the model. As a technology research and demonstration program, SuperTruck is also responsible for diffusing high-efficiency technologies into conventional powertrains as well. Nevertheless, in terms of encouraging adoption of SuperTruck powertrains, Figure $7 \mathrm{~d}$ depicts the tradeoff space between SuperTruck purchase premiums and efficiency improvements. Similar to Figure 6b, cost and efficiency multiplier values of zero indicate zero difference with the CI powertrain in 2050, but here the efficiency multiplier denotes improvement. The contour lines suggest sharp sensitivity to lower (but not higher) SuperTruck purchase premiums, but relatively little dependency on the magnitude of the efficiency benefit. The contour lines are also stacked closely together, suggesting a high elasticity of demand for ultra-efficient diesel trucks. 


\subsection{Different Niches for $C N G$ and $L N G$}

Figure 8 affirms conclusions deduced from earlier plots. When economic conditions favor adoption of NGVs, for instance cheap natural gas and expensive oil as shown in Figure 8a, CNG and LNG trucks play different roles. Of all the ton-mileage traveled by the HDV stock, the fraction fueled by LNG is shown in Figure 8b. The contours in LNG ton-mileage fraction and total NGV stock fraction are actually quite similar, with higher LNG ton-mileage fractions than NGV stock fractions. Thus, despite the many CNGs on the road at high oil prices, the use of LNG trucks in the heaviest ton-mileage segment gives LNG a much bigger share of the ton-miles traveled. The full stock breakdown by powertrain and refueling station type is shown in Figure 8c for variations in oil price. LNG trucks, and even LNG SuperTrucks, dominate in the long haul segment and CNG trucks are adopted heavily in the private fleet, urban operations segment.

[Figure 8 about here.]

As LNG and CNG become more economical in their different HDV niches, other parameters become influential as well, albeit in secondary roles. Figures $9 \mathrm{a}$ and $9 \mathrm{~b}$ show the impact of infrastructure related parameters on LNG ton-mileage fraction. Contours in Figure 9a show sensitivity to the $y$-axis, the rate of public refueling infrastructure growth relative to truck sales (Equation 11), but only at higher oil prices. Thus, infrastructure availability does not impact LNG adoption if the fuel price differential does not favor LNG operation in the first place. Similarly, the station density threshold for fleet owners to consider an alternative fuel $\left(\theta^{0}\right.$ in Equation 4 ) is plotted along the $y$-axis in Figure $9 \mathrm{~b}$. As before, LNG ton-mileage is 
only sensitive to this parameter once the oil price multiplier is high enough. Plotting the CNG ton-mileage fraction for the same parameters as Figures $9 \mathrm{a}$ and $9 \mathrm{~b}$ (not shown) depicts variation along the $x$-axis only, consistent with Figure 8c. CNG ton-mileage is sensitive to other model parameters, such as the cost of supporting private infrastructure ( $q$ in Equation 10), that LNG ton-mileage is not. This is shown in Figure 9c, and unlike the other plots, there is sensitivity to the $y$-axis throughout the tradespace, as CNG is cost competitive even at baseline oil price projections for fleets with private infrastructure conducting urban operations (Figure 5b).

[Figure 9 about here.]

\subsection{Reducing Petroleum Use and HDV Emissions}

One of the stated goals of the recent EPA/NHTSA rule making for HDV efficiency standards is to reduce diesel fuel consumption and US dependency on petroleum. Petroleum consumption reduction in the model is shown in Figure 10. Obviously, oil prices higher than current projections strongly encourage AFV adoption and reductions in diesel demand, especially when combined with longer required payback periods that consider more years of fuel costs (Figures 10a and 10b). Another pathway towards significant reductions in petroleum demand is by investing in technology that improves the efficiency of all ICE-based powertrains (Figure 10b). Aiming for petroleum use reduction by directly subsidizing or incentizing advanced powertrains, such as SuperTruck, or alternative fuels, such as NGVs, is actually less influential by comparison even when accounting for the different multiplier extents (Figure 10c). This is because under baseline economic projections, traditional diesel trucks are still slated to be the 
dominant powertrain and contributor to fuel consumption through 2050.

[Figure 10 about here.]

Another stated goal of the EPA/NHTSA regulations is to reduce GHG and pollutant emissions from HDVs. This objective is captured in Figure 11, which shows well-to-wheels emissions reductions. As above, aiming to reduce GHG emissions by encouraging adoption of NGVs (Figure 11a) or SuperTrucks (Figure 11b) has little influence on per ton-mile GHG emissions. This is partly due to the fact that LNG trucks have higher GHG intensity at simulation end than CI powertrains (Figure 3c). The most effective means of reducing emissions of any type is to improve the fuel efficiency of all powertrains, which is reflected in the ICE efficiency multiplier. The model tracks many other pollutants as well and contours of per ton-mile emissions for these species are similar to those for GHG. However, pollutants with notably different emission profiles for diesel and natural gas powertrains demonstrate some intriguing tradeoffs. For instance, burning natural gas produces less $N O_{x}$ per unit energy than diesel, but when combined with the lower efficiency of natural gas vehicles, there can be some complex dynamics (Figure 3). Figure 11c shows contours of $N O_{x}$ emissions, as a percentage reduction of per ton-mile emissions in 2050 relative to 2012. Moving along the $x$-axis, as oil prices increase, there is a region of the tradespace where $N O_{x}$ emissions decrease and then increase. The decrease in $N O_{x}$ (higher reduction relative to 2012) is due to the adoption of CNG powertrains over CI powertrains, especially in the private refueling segment. As seen in Figure 3b, this switch leads to a reduction in $N O_{x}$ produced per ton-mile. Moving further along the $x$-axis, however, $N O_{x}$ 
emissions increase (lower reduction relative to 2012) due to the adoption of LNG trucks over diesel SuperTrucks in the long haul, ton-mile intensive segment (consistent with Figure 7). As seen in Figure 3b LNG trucks emit more $N O_{x}$ per ton-mile than the CIST powertrain, hence the complex dynamics in contour slope.

[Figure 11 about here.]

To reinforce the idea that promoting natural gas as an alternative fuel has a limited impact on GHG emissions reduction, an exaggerated scenario was devised that can be considered ideal for NGV adoption. In this scenario, oil price was double baseline projections by 2050, natural gas was half baseline projections in $2050, \mathrm{NGVs}$ achieved cost parity with conventional vehicles by 2050 and the average required payback period was extended to 6 years. The combined effect of these influences is enough to make NGVs approximately $60 \%$ of the HDV stock by 2050 (Figure 12a). Additionally, Figure $12 \mathrm{~d}$ shows that the penetration of NGVs is still confined to predominately long haul operations or large private fleets. In the small urban fleet segment, diesel powertrains are nearly $70+\%$ of the market. Nevertheless, the use of LNG in long haul operations means only $10 \%$ of the total stock ton-mileage runs on diesel (Figure 12b). This is also reflected in the comparison of petroleum reduction per ton-mile over time in Figure 12c, where the exaggerated scenario reaches a $90 \%$ reduction level relative to the beginning of the simulation. However, the GHG reduction per ton-mile is only 10 percentage points higher than the baseline case, underscoring that alternative fuels alone cannot meet the most aggressive GHG reduction targets, such as the $80 \%$ by 2050 goal (IPCC, 2007). The bulk of the reduction is driven 
by efficiency improvements for all powertrains, and as shown in Figure 11, investment in efficiency improvements is the most direct pathway for the HDV sector to do its part in meeting the $80 \%$ reduction by 2050 target.

[Figure 12 about here.]

\section{Conclusions and Policy Implications}

The numerical analysis has demonstrated that conventional diesel trucks will likely dominate the Class 7 and 8 segments through 2050. This conclusion is robust to a number of parametric explorations. Natural gas trucks will have a significant foothold in the HDV stock that could grow depending on some key economic (e.g., oil price) and industrial (e.g., NGV purchase price premiums) uncertainties. Not all NGVs are alike however. CNG is most appropriate for large fleets that conduct urban operations and can support private infrastructure. This role is already economically feasible and will continue to be given current commodity price projections. In contrast, LNG is most appropriate for long haul operations but is not currently economically attractive. This is due to the higher cost of LNG relative to CNG, the limited range of LNG trucks relative to diesel, and the vehicle purchase price premiums. LNG trucks would be more competitive with a higher fuel price differential, as might occur under higher oil price projections. However, LNG trucks may end up competing more with other advanced powertrains, such as diesel SuperTrucks, than conventional vehicles.

The benefit of the parametric analysis is that it directly identifies the key factors that most influence an output metric of interest. For instance, 
the introduction of alternative fuel vehicles consistently raises the dilemma of the infrastructure chicken-and-egg problem. Meaning, consumers will only buy alternative vehicles if the refueling infrastructure exists but infrastructure stakeholders are hesitant to invest in new fuels unless profit is assured. This dilemma is particularly acute for the adoption of heavyduty NGVs, as both LNG and CNG trucks are available, but the two fuels can have different and incompatible supply chains. The parametric analysis presented here can inform the infrastructure investment decisions for public natural gas refueling. Since the investment rate in new refueling stations only impacted LNG truck adoption, but not CNG truck adoption (Figures 9a and 9b), this analysis suggests that infrastructure investments in natural gas for heavy-duty applications should focus on LNG, not CNG. Furthermore, the results also suggest that build out of CNG stations for light-duty vehicles will not necessarily encourage adoption of CNG HDVs, as the two size classes are independent.

If policy makers wish to augment adoption of NGVs or SuperTruck platforms, this analysis has shown that reducing the purchase price premium of those powertrains is far more effective than improving their efficiency relative to conventional diesels (Figure $6 \mathrm{~b}$ and Figure $7 \mathrm{~d}$ ). For instance, policy makers should prioritize investments in technology to reduce the cost of CNG or LNG fuel tanks over technology investments that make natural gas engines as efficient as diesel. Adoption of NGVs and reduction in HDV stock petroleum use in particular can be stimulated by increasing the fuel price differential between diesel and natural gas (Figure 6a). Increasing the diesel fuel tax and/or reducing taxes on CNG and LNG, would be the most direct means of doing so, although they would have to be quite high to be on the 
scale of the multipliers examined here. Alternatively, policy makers could encourage fleet owners to consider more years of ownership costs or give greater access to capital for purchasing advanced or alternative powertrains. Both of these actions would serve to increase the average required payback period parameter explored in the analysis. One mechanism to extend fleet owners' required payback periods is through interest-free loans for advantage or alternative powertrains. The adoption of SuperTruck platforms and the reduction in petroleum demand would particularly benefit in that case. SuperTruck adoption showed a high elasticity of demand (Figure 7d), suggesting that incentivizing SuperTruck platforms, or stimulating diffusion of SuperTruck technologies into conventional powertrains would be welcome if they are cheap enough. The analysis also showcased the quantifiable impact of the SuperTruck powertrains on GHG emissions and petroleum use reduction (Figure 7c). The projected success of the SuperTruck program suggests that this type of government-industry collaboration is a template for future investments by decision makers. However, this analysis has also shown that incentivizing alternative or advanced powertrains has limited leverage over reducing total HDV stock emissions. Indeed, even in an exaggerated scenario devised to be ideal for heavy-duty NGV adoption, GHG reduction per ton-mile is only 10 percentage points higher than our baseline scenario, even though petroleum consumption reduction per ton-mile is more than 30 percentage points higher than the baseline case (Figure 12c). Since conventional diesels dominate the HDV segment through 2050, efforts to improve the efficiency of all powertrains, conventional, alternative, and advanced, is more efficacious (Figure 10 and Figure 11). Thus, policy makers should be wary of backing new alternative technologies without recognizing that 
traditional diesel vehicles will be a mainstay in the U.S. heavy-duty stock for many decades to come.

\section{Acknowledgments}

The authors are grateful to a number of individuals who have provided their comments and suggestions over the course of this work that have significantly improved the quality of research. Graham Williams and Alicia Birky provided valuable suggestions on modeling details and data availability. Graham Williams, Mike Gallagher, John Lapetz, Jacob Ward, Roland Gravel, Ken Howden, and Dennis Siebers all heard early presentations of this work and provided insightful comments and critiques.

This work was funded by the Laboratory Directed Research and Development program at Sandia National Laboratories. Sandia National Laboratories is a multi-program laboratory managed and operated by Sandia Corporation, a wholly owned subsidiary of Lockheed Martin Corporation, for the U. S. Department of Energy's National Nuclear Security Administration under Contract DE-AC04-94AL85000.

Argonne National Laboratory, 2014. GREET.net Lifecycle Model 2013. Argonne, IL. URL: http://greet.es.anl.gov.

Barter, G.E., Reichmuth, D., West, T.H., Manley, D.K., 2013. The future adoption and benefit of electric vehicles: a parametric assessment. SAE Int. J. Alt. Power 6 . doi:10.4271/2013-01-0502.

California Environmental Protection Agency, Air Resources Board, 2012. Facts About: Tractor-Trailer Greenhouse Gas Regulation. URL: http://www.arb.ca.gov/cc/hdghg/fact_sheets/ HDGHG_Genl_Fact_Sheet.pdf.

Cooper, C., Kamakat, F., Reinhart, T., Kromer, M., Wilson, R., 2009. Reducing HeavyDuty Long Haul Combination Truck Fuel Consumption and CO2 Emissions. Paul Miller (ed.). Northeast States Center for a Clean Air Future, International Council on Clean Transportation, Southwest Research Insitute, TIAX, Boston, MA.

Davis, S.C., Diegel, S.W., Boundy, R.G., 2014. Transportation Energy Data Book: Edition 33. ORNL-6990, Oak Ridge National Laboratory, Oak Ridge, Tennessee. 
Delorme, A., Karbowski, D., Vijayagopal, R., Sharer, P., 2009. Evaluation of Fuel Consumption Potential of Medium and Heavy Duty Vehicles through Modeling and Simulation. Argonne National Laboratory. Argonne, IL.

Gao, Z., LaClair, T.J., Daw, C.S., Smith, D.E., 2013. Fuel Consumption and Cost Savings of Class 8 Heavy-Duty Trucks Powered by Natural Gas. Technical Report TRB-13-2945. Transportation Research Board.

Greene, D.L., 2001. TAFV Alternative Fuels and Vehicle Choice Model Documentation. Technical Report TM-2001/134. Oak Ridge National Laboratory. Oak Ridge, TN.

IPCC, 2007. Climate Change 2007: Mitigation. Contribution of Working Group III to the Fourth Assessment Report of the Intergovernmental Panel on Climate Change. B. Metz, O.R. Davidson, P.R. Bosch, R. Dave and L.A. Meyer (eds.). Cambridge University Press, Cambridge, United Kingdom and New York, NY, USA.

National Petroleum Council, 2012. Advancing Technology for America's Transportation Future. Washington, DC.

National Research Council, 2010. Technologies and Approaches to Reducing the Fuel Consumption of Medium- and Heavy-Duty Vehicles. National Academies Press, Washington, DC.

National Research Council, 2012. Review of the 21st Century Truck Partnership, Second Report. National Academies Press, Washington, DC.

Puller, S.L., Greening, L.A., 1999. Household adjustment to gasoline price change: an analysis using 9 years of US survey data. Energy Economics 21, 37-52. doi:http://dx.doi.org/10.1016/S0140-9883(98)00006-1.

R. L. Polk \& Co., 2012. Vehicle Registration Database. Technical Report.

Silver, F., Brotherton, T., 2013. DRAFT: CalHEAT Research and Market Transformation Roadmap for Medium- and Heavy-Duty Trucks. Technical Report. California Hybrid, Efficient and Advanced Truck Research Center (CalHEAT).

Sperling, D., Kitamura, R., 1986. Refueling and new fuels: An exploratory analysis. Transportation Research Part A: General 20, 15-23. doi:http://dx.doi.org/10.1016/0191-2607(86)90011-7.

Struben, J., Sterman, J.D., 2008. Transition challenges for alternative fuel vehicle and transportation systems. Environment and Planning B: Planning and Design 35, 10701097.

TA Engineering, Inc., 2012. DOE SuperTruck Program Benefits Analysis. Baltimore, MD.

The White House, 2014. Improving the fuel efficiency of American trucks-bolstering energy security, cutting carbon pollution, saving money and supporting manufacturing innovation. URL: http://www.whitehouse.gov/sites/default/files/docs/finaltrucksreport.pdf.

TIAX LLC, 2012. U.S. and Canadian Natural Gas Vehicle Market Analysis: Liquefied Natural Gas Infrastructure. Lexington, MA. URL: http://anga.us/issuesandpolicy/transportation/tiaxnaturalgasvehiclemarketanalysis.

U.S. Census Bureau, 2002. Vehicle Inventory and Use Survey (VIUS).

U.S. Department of Energy, 2012. Alternative Fueling Station Counts by State. URL: http://www .afdc.energy.gov/fuels/stations_counts.html.

U.S. Department of Energy, 2014. Vehicle and Infrastructure Cash-Flow Evaluation (VICE) Model. 
U.S. Department of Energy: Vehicle Technologies Office, 2013. 21st Century Truck Partnership Roadmap and Technical White Papers. URL: http://cms.doe.gov/eere/vehicles/downloads/roadmapand-technical-white-papers-21st-century-truck-partnership.

U.S. Department of Transportation Bureau of Transportation Statistics, U.S. Department of Commerce Census Bureau, 2012. Transportation: 2012 Commodity Flow Survey. Technical Report Table 1 Shipment Characteristics by Mode of Transportation for the United States.

U.S. Department of Transportation Federal Highway Administration, 2010. The Freight Analysis Framework. Technical Report Version 3.

U.S. Energy Information Administration, 2014. Annual Energy Outlook 2014: with Projections to 2040. Technical Report DOE/EIA-0383(2014).

U.S. Environmental Protection Agency and U.S. Department of Transportation, 2011a. Final Rulemaking to Establish Greenhouse Gas Emissions Standards and Fuel Efficiency Standards for Medium- and Heavy-Duty Engines and Vehicles Regulatory Impact Analysis. Technical Report EPA-420-R-11-901.

U.S. Environmental Protection Agency and U.S. Department of Transportation, 2011b. Regulatory Announcement: EPA and NHTSA Adopt First-Ever Program to Reduce Greenhouse Gas Emissions and Improve Fuel Efficiency of Medium- and Heavy-Duty Vehicles. Technical Report EPA-420-F-11-031.

Werpy, M.R., Santini, D., Burnham, A., Mintz, M., 2010. Natural Gas Vehicles: Status, Barriers, and Opportunities. Technical Report ANL/ESD/10-4. Argonne National Laboratory. Argonne, IL.

Whyatt, G., 2010. Issues Affecting Adoption of Natural Gas Fuel in Light- and HeavyDuty Vehicles. Technical Report PNNL-19745. Pacific Northwest National Laboratory. Richland, WA.

Yeh, S., 2007. An empirical analysis on the adoption of alternative fuel vehicles: The case of natural gas vehicles. Energy Policy 35, 5865-5875.

Zhao, H., Burke, A., Miller, M., 2013. Analysis of class 8 truck technologies for their fuel savings and economics. Transportation Research Part D: Transport and Environment 23, 55-63. doi:http://dx.doi.org/10.1016/j.trd.2013.04.004. 


\section{List of Figures}

1 High-level diagram of the model components. . . . . . . . . 38

2 Baseline projections and parameterization range for commodity prices, truck costs, and truck efficiency. Costs are shown in 2012USD. . . . . . . . . . . . . . . . . . . . 39

3 Baseline projections for per ton-mile, well-to-wheel emissions intensities of PM2.5, $N O_{x}$, and GHG. . . . . . . . . . . 40

4 Baseline HDV stock fractions, sales, and load specific fuel consumption over time. . . . . . . . . . . . . . . . . . . 41

5 Baseline HDV stock fractions by fleet size and refueling station type segments over time. . . . . . . . . . . . . . . 42

6 Contours of diesel and natural gas truck sales in 2050. Baseline represents default values in the model for the $x$ and $y$ variables. . . . . . . . . . . . . . . . 43

7 Contours of NGV and SuperTruck sales in 2050. Baseline represents default values in the model for the $x$ and $y$ variables. 44

8 Differing niches in the HDV marketplace for LNG and CNG trucks. Baseline represents default values in the model for the $x$ and $y$ variables. . . . . . . . . . . . . .

9 Contours of $2050 \mathrm{CNG}$ and LNG ton-mileage fractions and sensitivities to secondary refueling parameters. Baseline represents default values in the model for the $x$ and $y$ variables.

10 Contours of reduction in petroleum use per ton-mile in 2050 relative to 2012. Baseline represents default values in the model for the $x$ and $y$ variables. . . . . . . . . . . .

11 Contours of reduction in well-to-wheel GHG and $N O_{x}$ emissions per ton-mile in 2050 relative to 2012. Baseline represents default values in the model for the $x$ and $y$ variables. .

12 HDV stock fractions and fuel mileage fraction for exaggerated scenario and comparison to baseline projections. . . . . . . . 


\begin{tabular}{|c|c|c|c|}
\hline Energy source & Source demand & Fuel production & Fuel demand \\
\hline sub-model & Source price & sub-model & Fuel price sub-model \\
\hline
\end{tabular}

Figure 1: High-level diagram of the model components. 


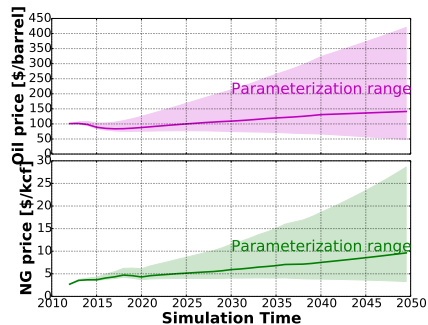

(a) Baseline commodity prices and parameterization range

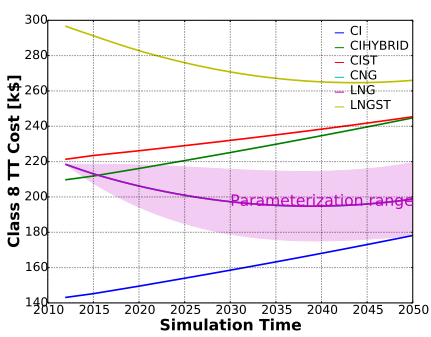

(c) Baseline purchase costs and parameterization range, Class 8 Tractor Trailer (TT) truck

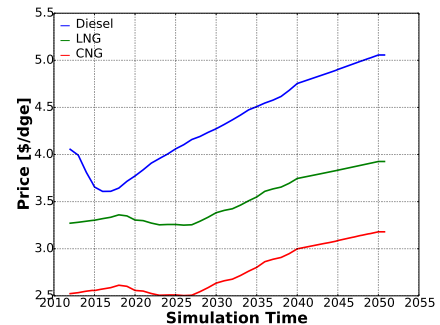

(b) Baseline fuel prices (parameterization not shown)

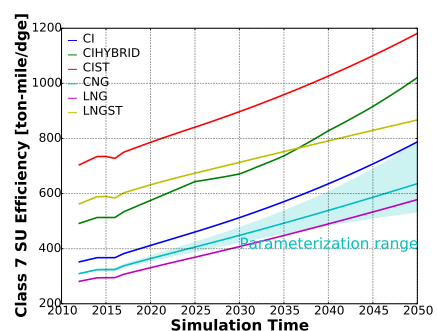

(d) Baseline vehicle fuel economy and parameterization range, Class 7 Single Unit (SU) truck

Figure 2: Baseline projections and parameterization range for commodity prices, truck costs, and truck efficiency. Costs are shown in 2012USD. 


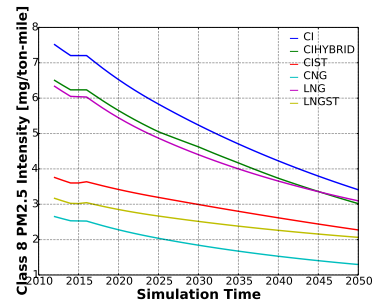

(a) PM2.5

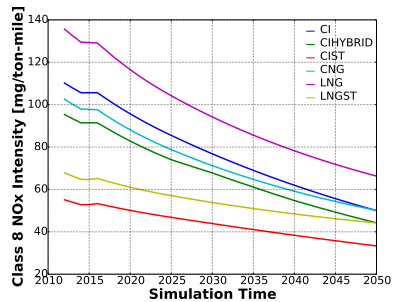

(b) $N O_{x}$

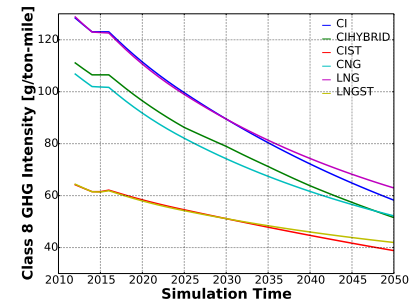

(c) GHG

Figure 3: Baseline projections for per ton-mile, well-to-wheel emissions intensities of $\mathrm{PM} 2.5, \mathrm{NO}_{x}$, and GHG. 


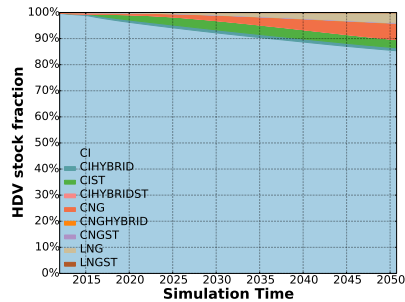

(a)

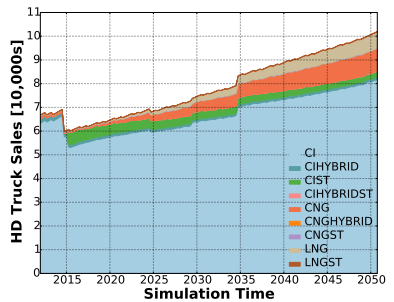

(b)

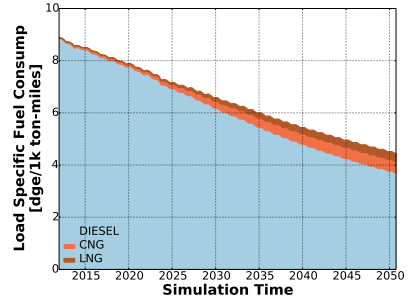

(c)

Figure 4: Baseline HDV stock fractions, sales, and load specific fuel consumption over time. 


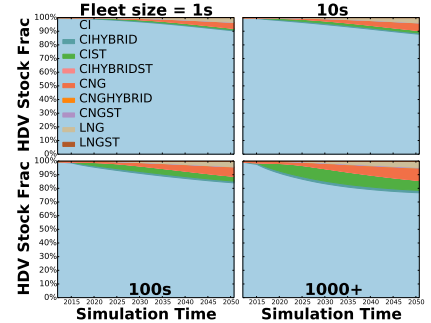

(a)

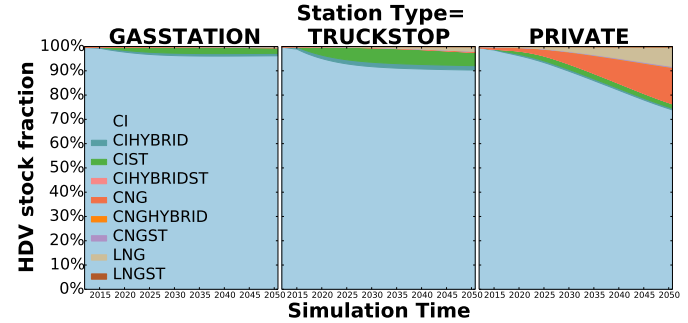

(b)

Figure 5: Baseline HDV stock fractions by fleet size and refueling station type segments over time. 


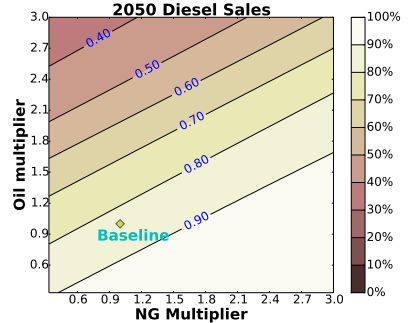

(a)

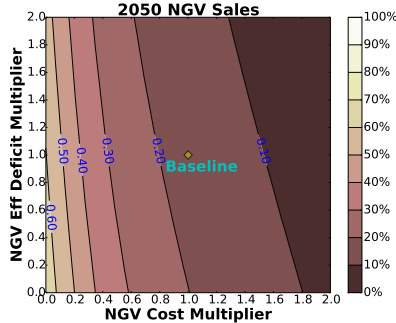

(b)

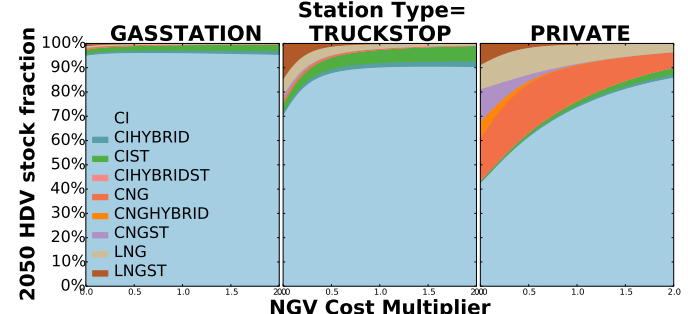

(c)

Figure 6: Contours of diesel and natural gas truck sales in 2050. Baseline represents default values in the model for the $x$ and $y$ variables. 


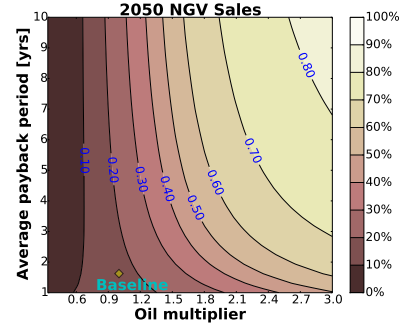

(a)

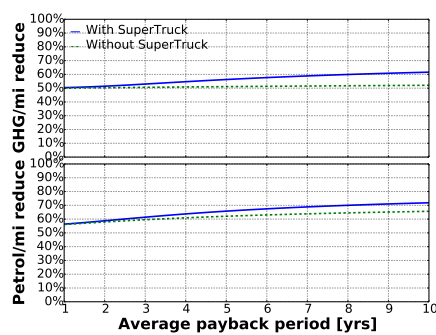

(c)

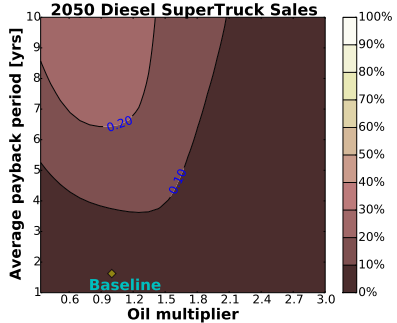

(b)

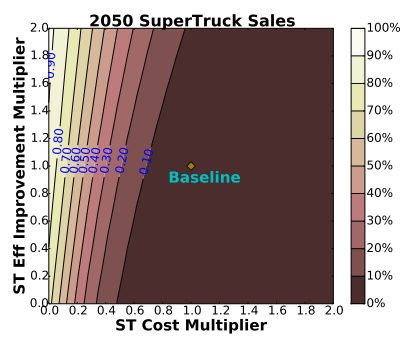

(d)

Figure 7: Contours of NGV and SuperTruck sales in 2050. Baseline represents default values in the model for the $x$ and $y$ variables. 


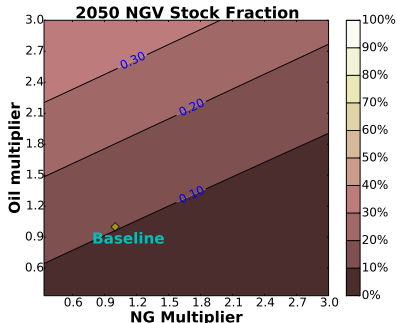

(a)

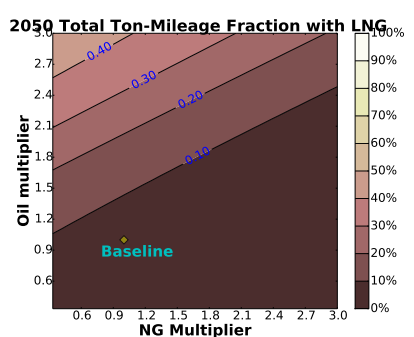

(b)

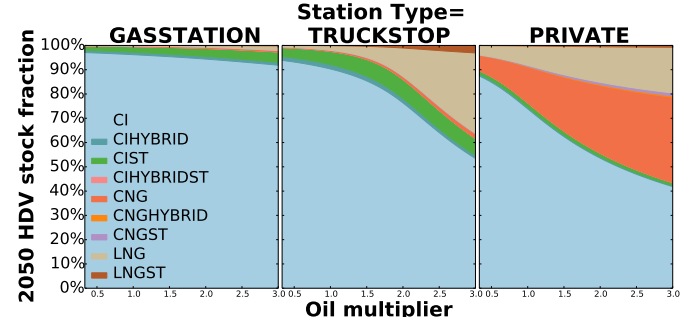

(c)

Figure 8: Differing niches in the HDV marketplace for LNG and CNG trucks. Baseline represents default values in the model for the $x$ and $y$ variables. 


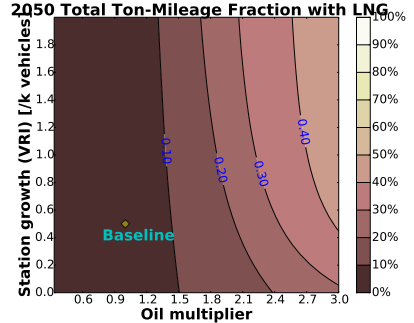

(a)

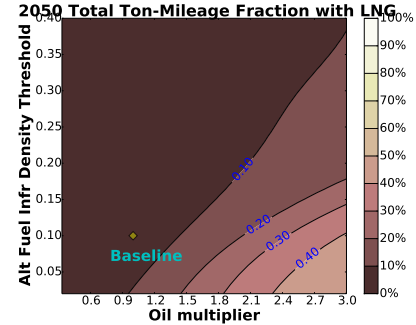

(b)

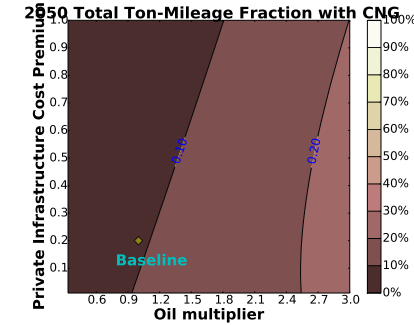

(c)

Figure 9: Contours of 2050 CNG and LNG ton-mileage fractions and sensitivities to secondary refueling parameters. Baseline represents default values in the model for the $x$ and $y$ variables. 


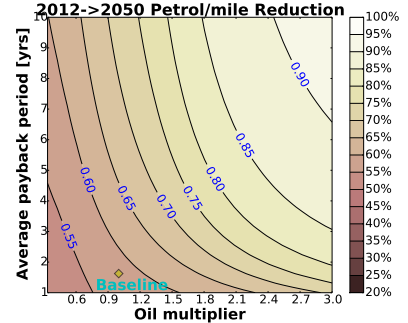

(a)

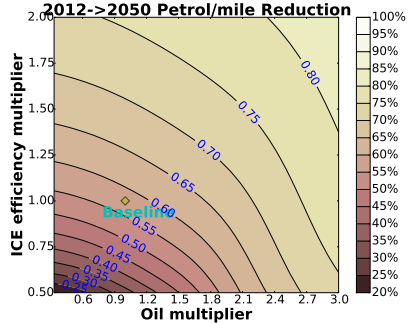

(b)

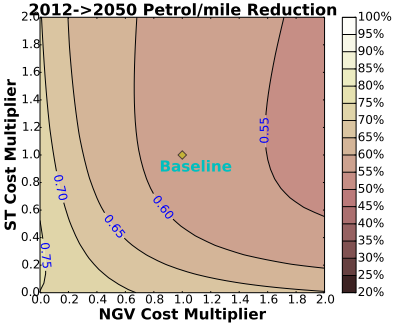

(c)

Figure 10: Contours of reduction in petroleum use per ton-mile in 2050 relative to 2012 Baseline represents default values in the model for the $x$ and $y$ variables. 


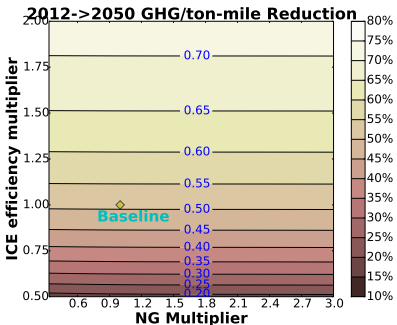

(a)

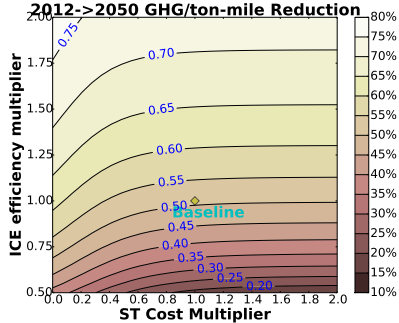

(b)

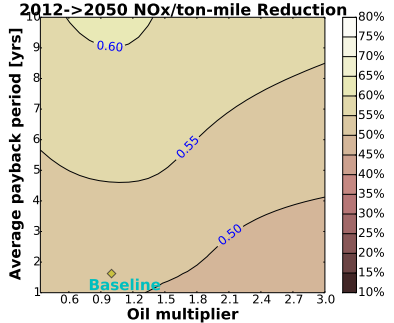

(c)

Figure 11: Contours of reduction in well-to-wheel GHG and $N O_{x}$ emissions per ton-mile in 2050 relative to 2012. Baseline represents default values in the model for the $x$ and $y$ variables. 


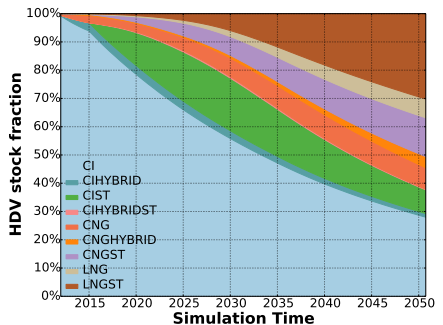

(a)

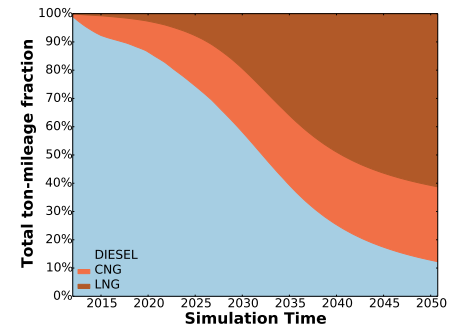

(b)

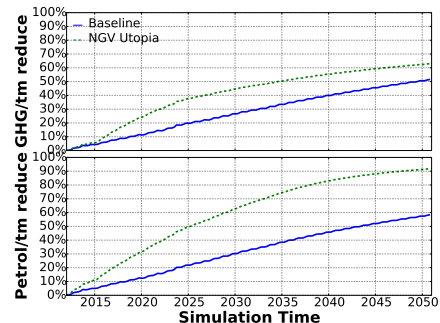

(c)

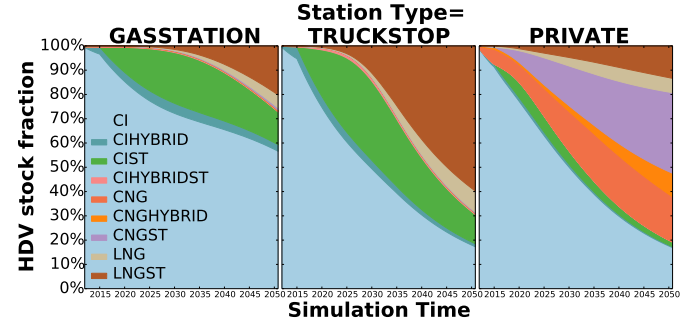

(d)

Figure 12: HDV stock fractions and fuel mileage fraction for exaggerated scenario and comparison to baseline projections. 